\title{
CORRECTION
}

View Article Online

View Journal I View Issue

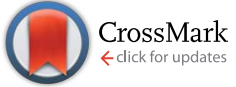

Cite this: RSC Adv., 2016, 6, 91658

\section{Correction: Rhodium-doped titania photocatalysts with two-step bandgap excitation by visible light- influence of the dopant concentration on photosensitization efficiency}

\author{
J. Kuncewicz ${ }^{\star a}$ and B. Ohtani ${ }^{b}$ \\ Correction for 'Rhodium-doped titania photocatalysts with two-step bandgap excitation by visible light- \\ DOI: $10.1039 / c 6 r a 90093 c$ \\ www.rsc.org/advances \\ influence of the dopant concentration on photosensitization efficiency' by J. Kuncewicz and B. Ohtani, \\ RSC Adv., 2016, 6, 77201-77211.
}

The authors regret that sub-labels are missing from the images in Fig. 6 of the original article. A revised version of Fig. 6, in which the labels (a), (b), (c) and (d) have been added, is included herein.

(a)

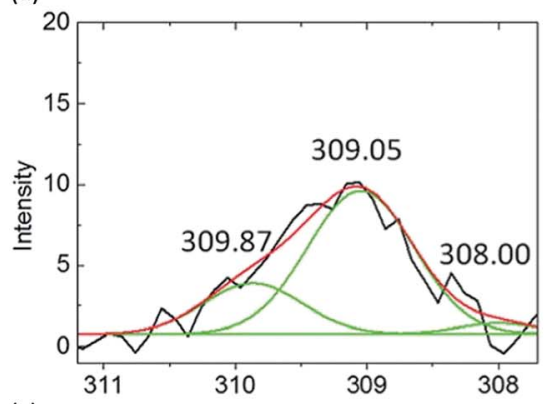

(c)

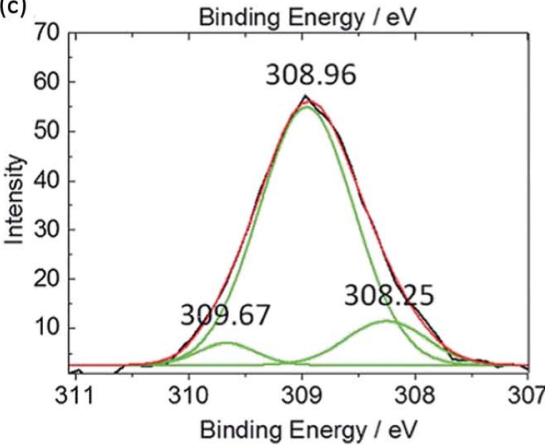

(b)

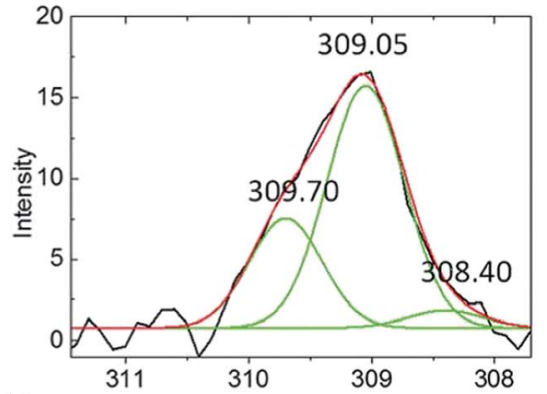

(d)

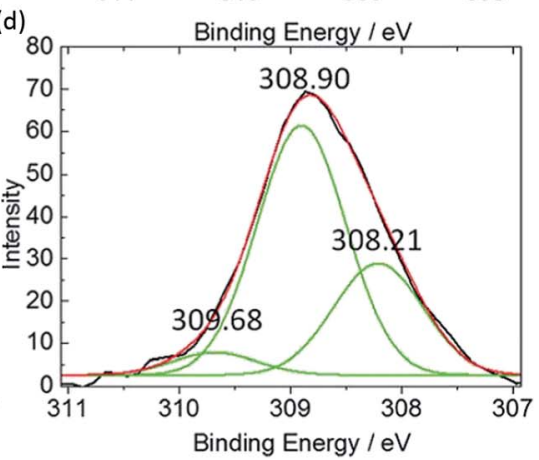

Fig. 6 Deconvolution of the $\mathrm{Rh}\left(3 \mathrm{~d}_{5 / 2}\right)$ signals recorded for $0.5 \%$ (a), $1 \%$ (b), $2 \%$ (c) and $3 \%$ (d).

The Royal Society of Chemistry apologises for these errors and any consequent inconvenience to authors and readers. 